\title{
Scientific and Theological Responses for Evolution and Biological Complexity
}

\author{
ANDRII KADYKALO \\ Lviv Polytechnic National University, Ukraine \\ andrii.m.kadykalo@lpnu.ua \\ ORCID: 0000-0003-0123-1671
}

\begin{abstract}
The article analyzes aspects of the relationship between evolution and biological complexity and the attempts made by scholars and theologians to interpret it within the limits of reductionist scientism or theism. For this purpose, firstly, attention is focused on explaining the meaning of the concept of «evolution» and its historical and philosophical transformation in the context of the idea of complexity. Secondly, the notion of complexity in theology is used as evidence to support teleology. This approach is criticized by some scholars who consider evolution as a random prosses. They give it the status of a universal metaphysical assumption in evolution. The scientists and theologists both formulate metaphysical assumptions differently to interpret evolution.
\end{abstract}

Keywords: teleology; randomness; organism; metaphysical assumptions.

\section{Introduction}

The concept of «evolution» is widespread and popular because it is used far beyond biology. In biology, this concept came from the philosophy where it originated (Juncker, Scherer 2002, 21-22). Evolution is firmly entrenched 
in biological vocabulary, and in general, biologists agree about its interpretation (Futuyma 2013; Freeman and Herron 2013). Although it would be inaccurate to say that it is not necessary to clarify the primary meaning and definition of the concept of «evolution». A contradictory interpretation of «evolution» can be related to what ideas will be part of its content or meaning (Millstein 2017). The ideas of direction, complexity, randomness, necessity, etc., can be part of the interpretation of the term «evolution» and become a common thematic research field for science and theology. This assumption is possible because the evolutionary interpretation of the processes of biological life has been significantly influencing the religious interpretation of the world and humanity.

Despite some researchers' remarks, the explanation of evolutionary processes poses no threat to the teleological argument in theism (Smedt, Cruz 2020, 6-7). As a process, evolution provokes a negative reaction from theologians only if given a sufficiently one-sided and simplistic interpretation because of the reductionism of individual scientists or materialist promoters of science. The scientists give their interpretation of evolution a universal status as the physical law. Therefore, it is necessary to find out the ideas that can be part of the meaning of evolution and how empirical data and its interpretation influence the confirmation or refutation of those ideas. It is crucial to find out whether reductionism follows from the theory of evolution since all.

It should be noted that most theologians and scholars agree with the existence of the interconnection of all living things (Barbour 1990; Polkinghorne 1994; Behe 2006; Küng 2007). Sometimes, it is believed that the differences in the interpretation of natural processes by science and religion are due to different terminology (Strumilowski Ocist 2019). This connection is the evolution treated by reductionists as the adaptation through random mutations from simpler life forms to more complex ones. Even the interpretation of evolution from reductionism's point of view requires an appeal to a certain kind of metaphysical assumption. One should agree that evolution's very notion will depend on the grounds and arguments for interpreting certain metaphysical assumptions. 
With this in mind, let us consider the concept of «evolution» from its inception and the gradual historic transformation of its content. We shall show that a part of the content of evolution is the notion of complexity. To clarify the possibility of forming certain interpretations of evolution, let us consider how the idea of complexity emerged and why it is associated with the concepts of progress, goal, and intention. In the third part of the article, we shall demonstrate how metaphysical assumptions are formed based on universal concepts. By comparing the concepts of Jacques Lucien Monod, Clinton Richard Dawkins, Paul Davies, John Polkinghorne, and Hans Küng, we will discern the difference in the ability of science and theology to use metaphysical assumptions in interpreting the consequences of evolutionary teaching.

\section{Evolution: historical transformation of concepts and ideas}

The need to explain the meaning of «evolution» to avoid an incorrect description of objects and phenomena may not appear very original. Biologists believe that the concept of «evolution» has a fixed meaning, and therefore do not pay much attention to its explanation. It is more common for the scholars in other disciplines, namely, philosophers and theologians, to claim that the concept of «evolution» is ambiguous and that its application should be delimited according to its functional purpose (Collins 2003, 256; Davies $2004,126)$. There is a distinction between the general biological concept of «evolution» and the universal concept (Collins 2003, 257). For example, Ayala said, «Evolution, theory in biology postulating that the various types of plants, animals, and other living things on Earth have their origin in other preexisting types and that the distinguishable differences are due to modifications in successive generations. The theory of evolution is one of the fundamental keystones of modern biological theory» (Ayala 2019). This definition is quite consistent with the formal requirements for a biological notion. However, since this is an analysis of the use and extrapolation of evolution into the field beyond biology, there is a need to clarify the term's 
etymology and function. Sometimes biologists seek to give this definition of «evolution» a universal status, and this becomes something different (Junker, Scherer 2002, 18; National Association of Biology Teachers 2008).

The Latin word «evolutio» means the unfolding, that is, the process of moving from narrower to wider, from smaller to larger, from simpler to more complex. Unfolding has several meanings, including «... straighten something folded; ... to give something its natural form; ... to make something accessible, open to sight.» This explanation of «evolution» can be supplemented. If «evolution» is a process of unfolding, then it means that the unfolded is taken from what has been laid, planned, existed in some other form (potential), but became real (material). In this interpretation, a teleological argument arises, namely, if a particular process unfolds from a potential to a real one, then it must have a particular focus on something, be for something, or have a specific purpose. Aristotle first formulated the teleological argument of explaining the origin and interconnection of all living things. This ancient thinker developed a system of classification of all living things in nature. His system has a hierarchical structure and purposiveness, that is, the explanation for the existence of all living organisms (Edelstein 1944, 150). The teleological character of Aristotle's concept influenced the Christian interpretation of the development of life, in particular. His interpretation was approved by Saint Augustine in the Middle Ages. The medieval thinker undertook to incorporate Aristotle's teleological conception into Christian doctrine, stating that «No maker is more excellent than God, no design is more efficacious than God's Word...» (Augustine 2018, 229). Later, in the 17th century, Archbishop James Ussher, following Aristotle's teaching on the Great Chain of Being in Genesis, claimed that «God created an infinite and continuous series of life forms, each one grading into the next, from simplest to most complex, and that all organisms, including humans, were created in their present form relatively recently and that they have remained unchanged since then» (Palomar 2012). Ussher did not favour evolutionary theory or evolutionism in their modern sense. However, in the very idea that God creates forms from simpler to more complex, one can see some features of evolution, namely, the transition from simple to complex. Such an 
assumption justifies the teleology of biological life and can be interpreted as a kind of synthesis of evolution and the idea of creation. Therefore, we cannot completely reject the assumption that the concept of «evolution» contains the purpose and the idea of complexity, particularly the development from simple to complex. Kant believed that our ideas about the direction of the development of living processes are related to a mechanistic understanding of the world. For him, living organisms are complex systems that are, in many ways, similar to complex artifacts made by humans (Ginsborg 2014). However, Kant states that the ability to reproduce and regenerate living systems is a sign of an absolutely new level. Kant's teleological argument has a goal that can be explained within naturalism (Allen, Neal 2019). Here we can see a noticeable change compared to previous ideas about life. In Kant's account, naturalism does not deny the existence of the Creator but changes the supernatural mechanisms of evolution's orientation to natural mechanisms. Unlike Haeckel, Kant does not consider a mechanism to be sufficient for explaining biological life (Kolb 1992, 9). It can be assumed that this leaves room for an idea of a certain desire for the orderliness of life.

One way or another, initially using the term «evolution» to refer to processes in biology, scientists transfer its meaning and neglect its origins. We suggest that since Darwin's time, this neglect has had a generally recognized status in biology (Junker, Scherer 2002, 24-25). The problem is that biologists commonly define the evolutionary process as something more significant, such as seen in the statement from the National Association of Biology Teachers (National Association of Biology Teachers 2008). Using the concept of «evolution», biologists refine its primary meaning, namely, removing from it the purposiveness (teleology) and complexity (the idea of higher development). Purposiveness and complexity are interrelated. One can even state that complexity is an argument to confirm purposiveness, the so-called «irreducible complexity» (Junker, Scherer 2006, 306). However, these concepts contradict the biologically acceptable notion of the neutrality of life-occurring processes, the emergence of species, etc., which are not subject to any guiding principles but to a combination of random gene changes and environmental influences. The purpose of evolution 
helps explain why a complex form of life emerges from the simple forms of biological life (Davies 2004, 111-112; Junker, Scherer 2002, 315-316). Only the expediency can explain the «desire» of life to reach an increased level of complexity. However, it is natural to ask biologists whether the desire to hold the idea of the universality of the theory of evolution is contrary to the principle of scientific objectivity. Is the idea of «evolution» without expediency and complexity, not an attempt to bring empirical data to a ready-made theory?

\section{The concept of complexity and its origin}

In modern biology, the complexity of biological life is problematic in the context of the interpretation of evolution. Its explanation is not reflected in the Declaration of Evolution, formulated by modern biologists (National Association of Biology Teachers 2008). Some researchers note that it is necessary to differentiate the concepts of evolutionary development and progress when it comes to evolution and its «orientation» towards complexity (Collins 2003, 280-281). The rejection of differentiation will result in the identification of the concepts of «evolution», «evolutionism», and «evolutionary theory». One could agree with this, but biologists sometimes seek to universalize evolutionary theory. In such circumstances, it is equated with evolutionism. The orientation towards progressive development gives evolution a direction, and this idea contradicts the «desire» of biologists to create the concept of «neutral» evolution. However, all the empirical evidence of the evolution of life on Earth supports a «progressive» evolution. This concept of evolution is the development in time (following the arrow of time from the past into the future) of the living from simpler to more complex or the emergence of life as such.

Initially, complexity in Ancient European philosophy was not equated with perfection, progress, etc. Plato believed that everything complex is not perfect because it consists of parts. The individual part is not independent, has no functional meaning in itself, unlike that which is integral, indivisible, and does not consist of separate parts. Hence comes the ancient notion that 
the soul is perfect and the body is not, because it consists of parts: «the soul is most like the divine, deathless, intelligible, uniform, indissoluble, always the same as itself, whereas the body is most like that which is human, mortal, multiform, unintelligible, soluble and never consistently the same» (Plato 1997, 70). The notion of perfection of the simple was also manifested in ancient philosophers' interpretation of cases with complex movement. In particular, Aristotle regarded it as a separate case of movement in a circle. The movement in a circle was considered perfect, absolute, and all other movement types are reduced as imperfect. Due to this, one can see the first signs of the idea that everything can be explained through the simple, and it will manifest later in physics and biology.

So when did the European philosophical tradition its perception of the relation of the perfect, the progressive, and the complex? We can assume that this was due to a combination of ideas about the Creator and the created. The intellectually grounded doctrine of the Creator was finally formed in medieval philosophy, particularly from the ideas of the Platonic Demiurge and Aristotle's teleology. In the «Confessions» of Augustine, what is created by the Creator is presented as good and is included in the associated series of complex and harmonic. «All beautiful bodies also express this; for a body which consists of members, all of which are beautiful, is by far more beautiful than the several members individually are by whose well-ordered union the whole is completed, though these members also be severally beautiful» (Augustine 1876, 387). The created has the status of «good» «Because it is from Him who is not in any degree, but He is that He is» (Augustine 1876, 390). The creation is conceived and planned, having a purpose through its Creator. However, such an idea is not sufficient to explain why the created causes compound creations with complexity. The completion of the transformation of the value of complexity can be explained by the interpretation of the role of a man and human intelligence in the process of creation. In the Middle Ages, people were not yet likened to God in their ability to create. The image of the human Creator appears in the Renaissance. Renaissance thinkers saw the harmony of the world, which they understood as perfection, and that was the consequence of the world being made in «the image of God». 
Giordano Bruno explained that the world is a harmonious work of God that can be studied by analogy with works of art (Tatarkiewicz 1999, 17). God the Creator, and man as the artist-creator. Such an analogy gives rise to the interpretation of the process of creation as directed toward a specific goal and the completion of a design. The creation process is complicated because it is always a combination of different elements that are intermediate links from idea to the embodiment. Achieving the ultimate goal is always a multilevel process, and, in modern scientific language, it is non-linear. Completed creation is a sign of complexity, so there must have been the one who conceived and created it. The development of science and the formation of mechanicism (Galileo, Newton) had two key implications for changing complexity perceptions. The first is that any system's complexity can be explained much more simply than was previously thought, and the second is that the Creator is not an artist, but rather an engineer. Creative artistic nonlinearity has been replaced by mechanical engineering linearity. Such ideas have been confirmed in practice, e.g., the development of mechanical production. To all this, the authority of Newtonian mechanics was confirmed by the universality of the law of gravitation which he had discovered and together with Kepler's laws that seemed to explain everything they called кó $\sigma \mu \mathrm{s}$, harmony, and order. All the grounds for interpreting complexity within deism have arisen.

The discoveries found while researching biological organisms showed that the notion about life in the meaning of complex mechanism was premature. The very word organism comes from the Latin «organismus» or «organizo», which means to tune, to give a clear structure. It contrasts sharply with the ancient Greek concept of ópravov, which meant an instrument, but it completely fitted into the ancient notion of the imperfection of the complex, that comprising of parts. In science from the 18th century and till the 20th-century, an organism is fundamentally different from a mechanism because it has three levels: molecular, cellular, and tissue. It became obvious that bringing the understanding of life to the physical and chemical levels is quite problematic. The assumption that the phenomenon of life can be explained on the basis of simple determinism was a naive reductionism. 
The success of biology and physiology in the 19th century explained the difference between animate and inanimate and the impossibility of identifying them, though it led to another problem. Establishing a physiological similarity between a human and other living beings overshadowed the fundamental difference between them. A human is always a unique personality. In other words, personality is one more, a higher level of complexity. This interpretation has a tradition well known in theology. Its roots can be seen in the concept of Augustine (Berry 2017, 95-99). This tradition contrasts with the approach of modern science. Science tends to simplify and reduce the personality purely to the network of neurons in the brain. It blurs the line between a living person, a personality, and the processes in his $\backslash$ her brain. A human can love and suffer. It would not be possible without the high level of complexity of the nervous system and brain. Can science explain, taking only on principles of evolutionism, what is the advantage of the human's ability to love, suffer, and sympathize? The uniqueness of a human for theology is incomparably higher than for science. Theologians believe that the ability to love and be faithful is inherent in God himself and, therefore, inherent in humans as his likeness (Polkinghorne 1988; Peacocke 1990, 121). The interpretation of life`s complexity explains its necessity and value, and reductionism in science can only assume its randomness.

\section{Interpretation of the relationship between evolution and the complexity of life in science and theology}

The functioning of biological organisms and the discovery of cellular structure has led to the understanding that life is a combination of sufficiently complex processes at different levels. Although the base of the living and the inanimate is on the level of elementary particles, life is much more complicated precisely because of its organization level. The structure of the organization of biological life includes regulation, control, and adaptation, the interaction of which determines the evolutionary processes at the level of an individual organism and species (Mainzer 2015, 185-186). The complexity is also manifested in the fact that all biological processes can not 
be simplified deterministically to elementary particles (Schrödinger). A new level of organization means new characteristics. However, they are related, and both their chemical and physical properties affect the functioning of the biological organism. Without them, complex metabolic networks would not be possible.

Explaining all the details of biological complexity is directly related to whether evolution can be considered universal (Juncker, Scherer 2002, 47). It is necessary to find explanations for the transformation mechanisms from unicellular organisms to humans (Juncker, Scherer 2002, 47). It is necessary to explain the essence of complex life if simple organisms are adapted well enough, and why the nervous system, brain, etc. emerge. If one rejects any direction to evolution, it is necessary to abandon the fact that the direction of evolution may be an adaptation, survival of the species, etc. However, the problem of complexity in evolution cannot be eliminated in such a simple way. Proponents of the universal action of randomness in evolutionary processes often use an argument that has a tautology in its essence: «Those organisms that are better suited for survival will survive more successfully.» This assertion has undergone a well-founded criticism (Davies 2004, 126). Not only is this argument tautological, but its problem is also that it cannot be empirically verified or reproduced. It is not reproducible in time, because the survival would have occurred in the past under unknown conditions. For example, is it possible to explain the nervous system's appearance, eye, or brain at some stage of evolution due to random events? Biologists have well understood this problem since the mid-20th century.

French molecular biologist Jacques Monod has taken a critical view of the concept of «evolution» in a sense it has had etymologically, traditionally, and it was similar to dialectical materialism.One can assume that he opposes a notion of «evolution», which contains ideas of progressive orientation and complexity (Monod 1972, 44). Although Monod does not mention this, in fact, he changes the concept of causality in discussing the emergence of life and the formation of new biologically complex species. Causality cannot be determined by purposiveness, since changes in organisms considered adaptive are random. There can be many factors that determine changes at 
the level of molecules, so it is impossible to predict their influence over an organism's mutation, as their variability is difficult to predict. Changes in DNA occur spontaneously and unpredictably, so there are no mechanisms of universal evolution. Monod eliminates any options for interpreting matter or unreasonable nature as being endowed with special «vital» properties (Bergson, de Chardin). Admittedly, he rightly regards them as unscientific.

Analyzing his ideas, we can assume that he opposes the creation of any outlook position that biology disproves. By rejecting the possibility of "progressive and directed evolution», Monod refutes the materialist Marxist interpretation of matter development. This means that evolutionary processes cannot be understood or predicted. Merely a case in which there is no pattern, and therefore it is complicated, if not impossible, to reconstruct life conditions. Monod's arguments have implications for the interpretation of the complexity of life and biological organisms. Complexity is accidental since it is a coincidence of circumstances and conditions of the properties of fundamental physical and chemical processes. This assumption shows that there is no directionally progressive evolution. It can be thus concluded that the interpretation of the processes of life formation and their functioning does not give grounds to expect that a universal theory of evolutionary development with laws is possible (Monod 1972). Empirical data from research findings support the concept of Monod.

Monod's concept became the basis for the ideological justification of the criticism by Richard Dawkins of any conception of the direction of the evolutionary process and the interpretation of biological complexity. Dawkins introduced the concept of the «Blind Watchmaker» as opposed to the deistic notion of God-the-Engineer. He criticizes the idea of progressive complexity, arguing that living organisms are complex but not perfect, which means not progress but adaptation. Monod and Dawkins, in their conception, provide randomness with universal character. From empirical evidence and hypotheses, they generally derive philosophical principles (Dawkins $2006,5)$. The assumption of chance as a universal, metaphysical, basis makes it possible to explain why there is neither hierarchically organized matter (dialectical materialism), nor a focus on progressive development (creation). 
The fallacy here is that Monod and Dawkins do not believe that they formulate a metaphysical thesis, from general to concrete, but rather rely on an inductive method. Their approach, going beyond the scientific, however, claims to be recognized as scientific. Also, the argument that randomness governs everything does not mean abandoning metaphysical assumptions. It can rather be interpreted as an attempt to solve the problem in a simple way. Is this possible for complex systems such as biological organisms and the biosphere as a whole? The assumption of the universality of chance in the emergence of biological life may be premature. Computer simulations of evolutionary systems demonstrate that specific patterns, the so-called evolutionary algorithms, may be found (R. Poli, C.R. Stephens 2014, 19-20). The discovery of evolutionary algorithms will not mean the destruction of the naturalistic interpretation of origin and nature of biological life. It will only refute the universality of the action of chance. However, it will be of significance which mechanisms are behind these evolutionary algorithms, namely, whether they are similar to those operating at the level of physical and chemical processes or whether they have a different fundamental basis.

The controversy surrounding the role of chance in biological processes indicates our incomplete knowledge of living systems, or that evolution is not universal. It differs from Monod's views. Even some neo-Darwinists recognize this problem. «All one can say is that since the first living organisms were presumably very simple, then if any large change has occurred in evolutionary lineage, it must have been in the direction of increasing complexity» (Maynard-Smith 1969, 82). In the assumption of the universal nature of chance there is also the problem of the ratio of utility and randomness. One needs to find out if random changes can be considered useful. They may even be harmful. Such changes may have a mosaic character or be a kind of analogue of «noise», that is, obstacles that distort or diminish useful information (Davies 2004, 109). Any organism is very complex, it is a system that is configured in a certain way. And even if some biologists believe that organisms are adapted to the environment but not perfect (in fact, this is an argument against the direction of evolution), organisms are still structured, that is, they are complex enough. How mathematically probable is it that 
such complexity and orderliness result from many random events? «At the heart of these misgivings lies the nature of random processes and the laws of probability. One does not have to be a mathematician to appreciate that the more intricately and delicately a complex system is arranged, the more vulnerable it is to degradation by random changes» (Davies 2004, 108). Paul Davies disagrees with Monod and Dawkins' assumption that a series of random events have shaped biological organisms' complexity. He gives an example of the biological complexity of the functioning and interaction of individual groups of molecules, each of which is a separate unit, but which performs the function of a part of the whole (Davies 2004, 100-101). Individual behavior is subject to general ordering. Like Monod, Dawkins tends to interpret the complex through its reduction to the elements and properties of the simple. For example, he explains the complexity of biological organisms' progressive tendency to avoid the loss of order. In such actions, one can see the desire to simplify, if not the biological organisms themselves, then at least the notion of them in biology. However, we have the reason to believe that a simplified understanding of complex biological systems and organisms is refuted. Computer simulation and the use of mathematical methods in studies of complex systems' behavior demonstrate that the operation of such a complex system as the organism cannot be regarded as a unity of simpler ones (Mainzer 2015, 186). It is similar to explaining the functions of DNA molecules based on their subatomic particle properties. It can be assumed that attempts to simplify the interpretation of complex systems are not a universal principle of science, but rather a certain assumption for interpreting empirical data for the universalization of all biological processes, both in nature in general and in individual organisms. This approach goes beyond the purely scientific and again comes out of a worldview nature.

Alternative approaches are also possible, and they will each have fundamentally different metaphysical assumptions. They hold that biological systems do not arise due to blind chance, but require some «irreducible complexity» (Behe 2006, 42). If we do not accept this assumption, «the existence of biological systems would be impossible» (Collins 2003, 288). The situation is clarified when one considers that biological organisms 
cannot be regarded as closed systems. Therefore we cannot extrapolate over them the characteristics inherent in physical and chemical systems. Usually, physical and chemical systems are closed and linear or considered as isolated and local systems. Physicists try to regard complex systems as special cases of simple systems (Rosen 1987, 315). Similarly, some biologists were inclined to explain the properties of a DNA molecule (Monod 1972). However, a biological system's interaction with the external environment is much more dynamic, and it is never completely isolated, so they are, in reality, open and nonlinear systems. Such systems' behavior is better explained not by the incidental action of many factors, but by external interference (Behe 2006, 192-193).

To identify a case of imposed design, you have to find a gap between what we see and the processes we know about that might have produced what we see, and you have to show that natural processes alone are not enough to bridge the gap. That is, there is a gap between the arrangement of the big stones in Stonehenge, and the properties of the stones and their environment (such as wind, rain, and earthquakes). There is a gap between the message-bearing function of DNA and the properties of the chemicals that make it up. There is a gap between human capacities for reason, language, and morality, and what we find in every other animal. From these gaps we conclude that it took some kind of special action, done by an agent, to bridge the gaps (Collins 2003, 289).

This position is rather weak because it suggests an explanation that contradicts science. However, it should be kept in mind that science is an open system of evolving knowledge, and therefore, something not currently explained can be explained in the future. The correctness of such an interpretation has been proven over time. The appeal to this argument already has its explanation in cognitive religious studies (Alex 2018).

Most theologians tend to accept the idea of evolution because they do not consider it contrary to the idea of creation (Polkinghorne 1994, 86; Küng 2007, 154; Collins 2003, 298-99). However, Stephen Jay Gould, Richard Dawkins, and Francisco Ayala (Dembski 1992) demonstrate that evolution and creation are not compatible. Their argument is based on the attempt to 
present the identification of complexity and perfection allegedly present in the concept of creation. None of the theologians believes that complexity should be referential, complete, and perfect. On the contrary, if we look for evidence that the complexity of living organisms is directed, the ability to transform under the influence of the changing external world only emphasizes this feature: «A world of hierarchical levels seems to have an inherent tendency to move toward emergent complexity, life, and consciousness. A patient God could have endowed matter with diverse potentialities and let it create more complex forms on its own» (Barbour 1997, 246).

Küng is convinced that the basic principles of evolutionary theory are undeniable. He acknowledges the validity of Monod's critical reaction to all attempts to introduce into the theory of evolution the notion of «evolutionary force or energy» that drives evolution. This recognition can be attributed to the fact that the Swiss theologian clearly separates empirical science methods and the «mystery» of the mechanisms of creation. Küng, together with other well-known contemporary theologians (Polkinghorne 1991, 46; Barbour 1990, 122), urge that God the Creator should not play the role of the one covering up the unknown, that of unfinished knowledge, and the God of «blind spots». Randomness, as Küng stresses, in no way undermines the existence of laws. He considers neither accident nor pattern to be universal. It is their common effect, which is universal. It is not a synthesis, nor a dialectical unity and development of opposites, but an influence on the organization of complex systems. The Swiss theologian interprets this randomness in terms of chaos theory.

In fact, such a system, in which solutions are irregular and periods cannot be established, can be predicted at best in the short term and in the long term not at all. The network of causal partial systems is so complicated that the resultant pattern of movement seems to be "chance". Chaos theory nevertheless now attempts with the help of computers to give a mathematical and physical description of such dynamic systems (for example, in fluid mechanics, electronics, or quantum mechanics) characterized by a determined chance behavior and the formation of chaotic structures. All this means that causal connections remain even in "chaos" and order can be established even in chaotic disorder (Küng 2007, 142). 
Randomness is not completely accidental and not universal. It is a testament to the complexity of organized systems (Küng 2007, 143). Randomness creates the opportunity for variability and the emergence of new structures. Thus, modeling the behavior of complex systems using empirical data provides no basis to reject the interconnection between the complexity of biological life and the direction of evolution (Küng 2007, 143-144). Regularity outlines the limits of the realization of chance, which leaves arguments for interpreting the direction of evolution and teleology. It avoids the «blending» of scientific and theological. Like some other theologians (Polkinghorne 1994, 79), he brings out the idea of creation beyond the narrow limits of the Creator's mechanisms of action in the conditions and parameters of empirically given material reality. In his explanation, Küng does not go beyond the tasks that confront theology. Scientific knowledge is not reliable for metaphysical assumptions, and theology can interpret scientific knowledge within metaphysical assumptions (Küng 2007, 144-145).

\section{Conclusions}

It can be concluded that the concept of «evolution» has a more ancient origin than the basic principles of the modern theory of evolution, and this has led to differences in the definition of the concept in different fields of knowledge. It is important to note that the concept of «evolution» has been substantially related to the Christian ideas of creation and teleology. This laid the ground for a confrontation between biologists who reject teleological evolution and theologians. The use of the idea of the complexity of biological life, which is interpreted by theologians as proof of teleology and «progressive» evolution, has led to criticism by some scholars. This criticism led to a change in the most fundamental principles in interpreting evolution, namely, to a revision of its metaphysical assumptions about the causes of complex biological systems' emergence and development. Some scientists (Monod, Dawkins), using empirical data, made attempts to prove that beyond the natural, unreasonable, and incidental boundaries, teleology and intelligent design are not noticeable, but these attempts 
can be considered as non-science. Based on scientific data interpretation, they formulate metaphysical assumptions about evolution, contrary to the principle of scientific objectivity. On the other hand, modern theologians do not seek to equate theology with the natural sciences in explaining the mechanisms of the origin of life, because it is beyond the scope of its tasks, which, above all, damages the theistic conception of the Creator. Further exploration of the interpretation of the concept of «evolution» and the idea of complexity may better understand which processes can be considered evolutionary. An additional search for notions (linearity, nonlinearity, hierarchy, and synergy) is needed that can influence the meaning of the concept of «evolution», which will contribute to a consistent understanding of the term and avoidance of metaphysical speculation.

\section{References}

Alex, Bridget. 2018. "The Human Brain Evolved to Believe in Gods.” Discover. October 15. https://www.discovermagazine.com/planet-earth/the-human-brain-evolvedto-believe-in-gods\#.XbB0EyjVIdg.

Allen, Colin, and Jacob Neal. 1996. "Teleological Notions in Biology.” Stanford Encyclopedia of Philosophy. https://plato.stanford.edu/entries/teleology-biology/ Augustine, Saint (Bishop of Hippo). 1876. The Confessions. Translated and annotated by Joseph G. Pilkington. Edinburg: T.\&T. Clark.

Augustine, Saint. 2018. The City of God. Abridged Study Edition. Introduction and translation William Babcock. New York: New City Press.

Ayala, F. Jose. 2019. "Evolution Scientific Theory.” Evolution. Encyclopædia Britannica. https://www.britannica.com/science/evolution-scientific-theory/ The-science-of-evolution

Barbour, G. Ian. 1990. Religion in an Age of Science. New York: Harper Collins Publishers.

Barbour, G. Ian. 1997. Religion and Science: Historical and Contemporary Issues. New York: Harper Collins Publishers.

Behe, J. Michael. 2006. Darwin`s Black Box: The Biochemical Challenge to Evolution. New York London Toronto Sydney: FREE PRESS.

Berry, John Anthony. 2017. „What makes us human? Augustine on interiority, exteriority and the self." Scientia et Fides 5(2): 87-106. 
Collins, C. John. 2003. Science and Faith: Friends or Foes? Wheaton: Crossway Books. Davies, Paul. 2004. The Cosmic Blueprint. Philadelphia and London: Templeton Foundation Press.

Dawkins, Richard. 2006. The Blind Watchmaker. London: Penguin.

Dembski, A. William. 1992. “Intelligent Design is not Optimal Design.” https://www. discovery.org/a/86/.

Edelstein, Ludwig. 1944. "Aristotle and the Concept of Evolution.” The Classical Weekly 37: 148-150.

Futuyma, Douglas. 2013. Evolution. Sunderland, MA: Sinauer Associates.

Ginsborg, Hannah. 2015. „Two Kinds of Mechanical Inexplicability in Kant and Aristotle." The Normativity of Nature: Essays on Kant's Critique of Judgement. Oxford Scholarship Online.

Herron, C. Jon, and Scott Freeman . 2013. Evolutionary analysis. London: Pearson.

Junker, Reinhard, and Siegfried Scherer. 2002. Evolucija ili Stvaranje. Belgrade: Preporod.

Kolb, Daniel. 1992. „Kant, teleology, and evolution.” Synthese 91: 9-28.

Küng, Hans. 2007. The Beginning of All Things: Science and Religion. Translated by John Bowden. Grand Rapids Cambridge: William B. Eerdmans Publishing Company.

Mainzer, Klaus. 2015. "Exploring Complexity: Von Artificial Life und Artificial Intelligence zu Cyberphysical Systems.” In Exploring Cybernetics, edited by Sabina Jeschke, Robert Schmitt, Alicia Dröge, 185-212. Wiesbaden: Springer.

Maynard, J. Smith. 1969. “The status of neo-Darwinism.” In Towards a theoretical biology, vol 2: sketches, editor by Waddington C. H., 82-89. Edinburgh: Edinburgh University Press. 1969.

Millstein, L. Roberta. 2017. “Evolution”. Stanford Encyclopedia of Philosophy. https:// plato.stanford.edu/entries/evolution/.

Monod, Jacques. 1972. Chance and Necessity: An Essay on the Natural Philosophy of Modern Biology. Translated by Austryn Wainhouse. New York: Vintage Books A Division of Random House.

National Association of Biology Teachers (NABT). 2008. "Statement on Teaching Evolution”. https://ncse.ngo/national-association-biology-teachers-2000.

Palomar College. 2012. "Pre-Darwinian Theories.” https://www2.palomar.edu/ anthro/evolve/evolve_1.htm.

Plato. Complete Works. 1997. Edited by John M. Cooper, D. S. Hutchinson. Indianapolis/ Cambridge: Hackett Publishing.

Poli, Riccardo, and Cristopher R. Stephens. 2014. "Taming the Complexity of Natural and Artifical Evolutionary Dynamics.” In Evolution, Complexity and Artificial Life, 
editors by Stefano Cagnoni, Marco Mirolli, Marco Villani, 19-42. Heidelberg New York Dordrecht London: Springer Publishing Company.

Polkinghorn, C. John. 1988. Science and Creation: The Search for Understanding. London, SPCK.

Polkinghorn, C. John. 1991. Reason and Reality: The Relationship Between Science and Theology. Salem: Trinity Pr Intl; 1st edition.

Polkinghorne, C. John. 1994. Science and Christian Belief: Theological Reflections of a Bottom-up Thinker. London: SPCK Publishing.

Rosen, Robert. 1987. "Some epistemological issues in physics and biology.” In Quantum Implications: Essays in Honour of David Bohm, 314-327, edited by Basil Hiley and F. David Peat. London: Routledge \& Kegan Paul.

Smedt, De Johan, and Helen de Cruz. 2020. The Challenge of Evolution to Religion. Cambridge: Cambridge University Press.

Strumilowski Ocist, P. Jan. 2019. „Complementarity and cohesion of the sophiologic and scientific vision of creation." Scientia et Fides 7(1): 207-25.

Tatarkiewicz, Władysław. 1999. Historia filozofii. T.2. Filozofia nowożytna do 1830 roku. Warszawa: Wydawnictwo Naukowe PWN. 